 \\ z Filologii Polskiej \\ i Słowiańskiej
}

\author{
Maria Papierz \\ (emerytowana profesor \\ Uniwersytetu Jagiellońskiego w Krakowie)
}

\section{Konstrukcje z predykatami percepcji w języku słowackim i ich ekwiwalenty w języku polskim}

\section{Konstrukcje accusativus cum infinitivo}

Predykaty percepcji stanowią semantyczną grupę predykatów II rzędu, tj. takich, które implikują nie tylko argumenty przedmiotowe, lecz także argumenty zdarzeniowe i mają strukturę semantyczną $\mathrm{P}(\mathrm{x}, \mathrm{q})$. Ze względu na jeden typowy dla języka słowackiego, a nieznany polszczyźnie sposób kondensacji argumentu zdarzeniowego q implikowanego tylko przy niektórych predykatach percepcji ograniczę się do opisu tylko tych predykatów percepcji słuchowej i wzrokowej. Chodzi o czasowniki typu: počut', u/vidiet' i ich (także nacechowane) synonimy: začut', s/pozorovat', vš́mat 'si/všimnút' si, z/badat', książk. uzriet' oraz czasownika nájst' w znaczeniu 'zastać', gdzie sem percepcji jest obecny: 'hladaním alebo mimovolne objavit, uvidiet’' (definicja hasła nájst', Kačala, \& Pisárčiková, 2003, s. 258)

Zaliczam tu też czasownik predstavit'si 'wyobrazić sobie' - czyli taki, który oddaje widzenie w myślach, oczyma wyobraźni.

This is an Open Access article distributed under the terms of the Creative Commons Attribution 3.0 PL License (creativecommons.org/licenses/by/3.0/pl/), which permits redistribution, commercial and non-commercial, provided that the article is properly cited. () The Author(s) 2017. 
Składnia predykatów percepcji - tu ograniczonych do predykatów percepcji słuchowej i wzrokowej w języku słowackim - w swoim szczególnym użyciu może być opisywana na różny sposób. W tradycyjnym opisie sięga się do terminologii łacińskiej nazywającej konstrukcje z tymi predykatami jako konstrukcje accusativus cum infinitivo, np. Videl Petra bežat., Počul Evu spievat'. Konstrukcję taką, znaną z języka łacińskiego i greckiego, zachowały m.in. języki słowacki i czeski, występowała ona też w staropolszczyźnie. Jak opisuje ją Stanisław Karolak: „Jest równoważna zdaniu podrzędnemu z ekwiwalencją accusatiwu i podmiotu tego zdania oraz infinitiwu i orzeczenia. Tak jest też oddawana w języku polskim” (Polański, 1999).

W tradycji słowackiej konstrukcja ta pojawia się w podręcznikach składni jako jeden rodzajów tzw. „doplnku” (słow. doplnok), należącego obok apozycji do pewnego typu kondensatów składniowych, nazywanych po słowacku „polovetné/polopredikatívne konštrukcie”. Obok bezokolicznika, np. w zdaniu Hlásnik zbadal niekoho približovat'sa $k$ veži. funkcję tę pełnią przymiotniki, rzeczowniki i imiesłowy, np. Chlapec chodí bosý., Človekú je smutno samotnému., Videl Elenu smutnú, so zvesenou hlavou. (Pauliny, 1981, s. 271). Podobnie opisuje wtórną predykację podręcznik Bajzíkovej i Oravca, traktując bezokolicznik w konstrukcjach accusativus com infinitivo jako „doplnok”:

Činnost vyjadrujú aj doplnky vyjadrené neurčitkom, ale tie sú ešte viac obmedzené ako prechodníkové a príčastové. Stoja iba pri prísudkových slovesách s významom vnímania (vidiet', počut', cítit...) a po slovese nájst.: Začul kornutu zablačat', Nik nikdy nevidel Púplavu pobehnút' (Oravec \& Bajzíková, 1986, s. 150).

Najobszerniej opisał „doplnok” w swojej monografii Ján Kačala (Kačala, 1971), który w klasyfikacji na „doplnok podmetný” i „doplnok predmetný” zaliczył konstrukcje z bezokolicznikiem do tego drugiego typu: Vídaval som ju prechádzat'sa po meste s bielym chrtom., Vtom začuje z ulice vykrikovat'Ruda Brda. Zalicza tu też predykatyw vidno: O chvílu už ho aj vidno kráčat' dolu dedinou., a także predykat cítit', choć uważa te użycia za rzadsze: Cíti príchodit' jar. (Kačala, 1971, s. 228). Najnowsze słowniki ich nie odnotowują.

Tak wyróżniona część zdania nie ma swojego odpowiednika w tradycyjnej składni polskiej, niektórzy badacze nazywają tego typu konstrukcje wtórną predykacją (Jodłowski, 1976) lub predykatywnym związkiem niezdaniotwórczym (Jedlička, 1977). Dotyczy to oczywiście predykacji wtórnej wyrażonej innymi niż bezokoliczniki konstrukcjami (przymiotnik, rzeczownik, imiesłów), gdyż accusativus cum infinitivo w funkcji „doplnku” oddawany jest w polszczyźnie 
konstrukcją imiesłowową lub zdaniem podrzędnym, por. prezentację wybranych predykatów percepcji.

Opracowania porównawcze słowacko-polskie (np. Sokolová, Vojteková, Mirosławska, \& Kyselová, 2012) także sytuują konstrukcje accusativus cum infinitivo w obrębie jednego z rodzajów „doplnku”, który, jak zauważają autorki podręcznika, nie ma swojego infinitywnego ekwiwalentu.

Dvojčlenným vetám $s$ verbami zmyslového vnímania doplnenými inými verbami $\mathrm{v}$ neurčitku zodpovedajú $\mathrm{v}$ polšstine vety s doplnkom vyjadreným príčastím alebo súvetia: Videla som ho vychádzat' $z$ domu. - Widziałam, jak wychodził $z$ domu/że wychodzit $z$ domu./Widziałam go wychodzacego $z$ domu., Bolo počut' hrat' hudbu. Było stychać grajaca muzykę/że gra muzyka., Našla som ho tam sediet'. - Zastałam go tam siedzacego. (Sokolová i in., 2012, s. 246)

Jedną z możliwych realizacji argumentu zdarzeniowego przy predykatach percepcji wzrokowej i słuchowej jest kondensacja w postaci imiesłowu przymiotnikowego czynnego. Często odpowiada ona w języku polskim bezokolicznikom w języku słowackim. Jak stwierdzają autorki opracowania porównawczego Slovenčina a polšstina...:

Aktívné perticípium imperfektív sa v obidvoch jazykoch používa na kondenzáciu textu, v polšstine sa však využíva častejšie. (...) Aktívne participium sa v polštine o. in. využíva v syntaktickej pozícii doplnku, v ktorej sa v slovenčine uplatňuje infinitív: Videla som ho fajčit. - Widziałam go palacego./... jak/że pali. V polštine sa tu viac využíva aktívne participium alebo vedlajšia veta: Počuli sme ju plakat. Styszeliśmy ja płaczącą./... jak/że płacze (Sokolová i in., 2012, ss. 248-249).

\section{Prezentacja wybranych predykatów percepcji}

Najpełniej możliwości realizacji predykatów percepcji opisuje model składni semantycznej zaproponowany przez Stanisława Karolaka $(1984,2002)$, gdzie każdemu $\mathrm{z}$ wybranych predykatów przypisuje się strukturę semantyczną $\mathrm{P}(\mathrm{x}, \mathrm{q})$, a na kolejnych etapach przybliżeń do struktur zdaniowych w języku naturalnym przedstawia się schematy eksplicytacji. Jak pisał Karolak:

Różnice istniejące między implikacyjnymi wymogami predykatów a konotacyjnymi właściwościami ich wykładników skłaniają do wyróżnienia dwóch modeli opisu propozycji. W płaszczyźnie pojęciowej są to formy logiczne (funkcje zdaniowe) symbolizujące relacyjne własności predykatów i immanentną strukturę propozycji, które konstytuują, natomiast w płaszczyźnie formalnej - schematy eksplicytacji symboli- 
zujące relacyjne własności wyrażeń predykatywnych i immanentną strukturę fraz, które konstytuują. Zadaniem tych ostatnich jest zdanie sprawy ze stopnia ujawnienia argumentów w strukturze formalnej, tzn. z różnicy między liczbą propozycji argumentowych otwartych przez predykaty a liczbą miejsc walencyjnych otwartych dla uzupełnień przez ich wykładniki. Formy logiczne (funkcje zdaniowe) są więc formami propozycji, natomiast schematy eksplicytacji są formami fraz. (Karolak, 2002, s. 153 i n.)

W schematach eksplicytacji fraz w zdaniach niezależnych zastosowano następujące skróty i symbole ${ }^{1}$ :

$\mathbf{P}$ - predykat;

$\mathbf{x}$ - pozycja argumentu przedmiotowego;

$\mathbf{q}$ - pozycja argumentu zdarzeniowego (propozycjonalnego);

W - symbol wykładnika predykatu wyższego (drugiego) rzędu zarówno głównego, jak i wewnętrznego;

V - symbol wykładnika predykatu pierwszego rzędu wewnętrznego (tzn. konstytuowanego przez argumenty propozycjonalne);

$\mathbf{N}_{\mathbf{x}}$ - symbol wyrażenia argumentowego (uzupełnienia), który oznacza wykładnik argumentu przedmiotowego najczęściej w postaci frazy nominalnej, indeks dolny ${ }_{\mathrm{x}}$ odsyła zaś do miejsca zajmowanego przez dany argument w układzie; $\mathbf{N}_{\mathbf{q}}$ - symbol wyrażenia argumentowego (uzupełnienia), który oznacza wykładnik argumentu propozycjonalnego;

$\mathbf{N}_{\mathrm{aq}}$ - argument „wyprowadzony” ze struktury propozycji zależnej od struktury propozycji jądrowej;

VI.../WI... - symbol wyrażenia predykatywnego w formie infinitiwu, taką formę argumentu zdarzeniowego konotuje bowiem predykat;

NV/NW $\mathbf{N}_{\mathbf{q}}$.. - symbol wyrażenia predykatywnego w formie nazwy abstrakcyjnej (rzeczownika odczasownikowego - spievanie, spev, lub odprzymiotnikowego - múdrost', dobrota);

$\operatorname{VAdj}_{\mathbf{q}} \ldots /$..WAdj $\mathbf{j}_{\mathbf{q}} . .$. - symbol wyrażenia predykatywnego w formie imiesłowu przymiotnikowego czynnego.

$\emptyset_{\mathbf{q}}$ - symbol wyrażenia predykatywnego wewnętrznego oderwanego od swoich uzupełnień lub niewypełnienia pozycji takiego wyrażenia.

1 Model ten został także zastosowany do całościowego opisu predykatów słowackich, Papierz (2013) oraz w monografii porównawczej Kiklewicz, Korytkowska, Mazurkiewicz-Sułkowska, Zatorska i Ramza (2010). 
Maria Papierz Konstrukcje z predykatami percepcji w języku słowackim i ich ekwiwalenty...

Subskrypty nom, acc oznaczają nazwy przypadków odpowiednio: mianownik i biernik.

Kolejność schematów eksplicytacji wynika z zasady, że najpierw podaje się schematy zawierające uzupełnienia leksykalnie wypełnione, potem schematy zawierające niewypełnione - bezkontekstowo - pozycje argumentów lub predykatów.

Materiał językowy pochodzi ze źródeł podanych na końcu tekstu, tj. słowników, podręczników oraz Słowackiego Korpusu Narodowego.

\section{Frazy zdaniowe}

\section{1. $\mathrm{W} \mathrm{N}_{\mathrm{x}}, \mathrm{V} / \mathrm{W}_{\mathrm{q}}$}

Czasowniki słowackie: cítit', počut', pozorovat', predstawit' si, u/vidiet', uzriet', všimnút si, zbadat'

Czasowniki polskie: czuć, dostrzec, u/słyszeć, widzieć, wyobrazić sobie, zauważyć

\section{Schemat zdaniowy}

$\mathrm{W} \mathrm{N}_{\text {nom }}$, (Pron) Con V/W...

Imro cítil, že je milovaný a obdivovaný. - Imro czuł, że jest kochany i podziwiany.

Matka počula, že dieta plače. - Matka ustyszała, że dziecko płacze.

Kameník pozoroval, že Mašliková pozvolna chradne. - Kameník obserwował, że Mašliková powoli mizernieje.

Predstavil si, že ho otec čaká doma. - Wyobraził sobie, że ojciec czeka na niego $w$ domu.

Osamelý muž uvidel, že ludia trpia. - Samotny mężczyzna zobaczyl, że ludzie cierpią. Peter uzrel, že práve prešiel okolo nej. - Peter zobaczyl, że właśnie przeszedł obok niej. Iva videla, že pán Golomb je štastný. - Iva widziała, że pan Golomb jest szczęśliwy. Anka si všimla, že dcérka sa usmieva. - Anka zauważyła/dostrzegła, że córeczka się uśmiecha.

Matka zbadala, že Miro vychádza z lesa. - Matka zauważyła, że Miro wychodzi zlasu.

Schemat zdaniowy $\mathbf{W} \mathbf{N}_{\text {nom }}$, (Pron) Con V/W... jest realizowany jednakowo w obu językach, tj. argument zdarzeniowy ma postać zdania podrzędnego $\mathrm{z}$ verbum finitum.

\section{2. $\mathrm{W} \mathrm{N}_{\mathrm{x}}, \mathrm{VI} / \mathrm{WI}_{\mathrm{q}} \ldots$}

Czasowniki słowackie: cítit', nájst', počut', predstavit' si, u/vidiet', uzriet', všimnút si, zbadat 
Czasowniki polskie: czuć, dostrzec, u/słyszeć, widzieć, wyobrazić sobie, zastać, zauważyć

\section{Schemat zdaniowy}

$\mathbf{W} \mathbf{N}_{\text {nom }}, \mathbf{V} / \mathbf{W}_{\text {inf }} \cdots$

Cítila sa byt dobre pripravená. - Czuła, że jest dobrze przygotowana. /...się dobrze przygotowana

Cíti príchodit jar. - Czuje, że nadchodzi wiosna. /... nadchodząca wiosnę.

Štefan našiel ženu sediet na gauči. - Štefan zastał żone, jak siedzi na tapczanie./... siedzaca na tapczanie.

Rozhlasový poslucháč počul moderátora kašlat. - Radiosłuchacz ustyszał, że spiker kaszle. /...kaszel spikera.

Predstavil si ho Melichar visiet niekde na strome. - Wyobrazit go sobie Melichar, jak wisi gdzieś na drzewie. /... wiszącego na drzewie.

Tam som po prvý raz videl a počul zápalisto rečnit Andreja Hlinku. - Tam po raz pierwszy widziałem i styszałem, jak Andrej Hlinka z zapałem przemawia. I ...przemawiającego z zapałem Andreja Hlinkę.

Vtedy som uvidel tancovat' svoju sestru. - Wtedy zobaczyłem, jak/że moja siostra tańczy. /... moją siostrę tańczaca.

Uzrel hračku visiet’ na šnúrke. - Ujrzał zabawkę wiszaca na sznurku. /...jak wisi na sznurku.

Vidím priatelov prichádzat. - Widzę, że przyjaciele nadchodzą. /...nadchodzacych przyjaciót.

Videl ju kráčat k bielemu svetlu. - Widział ją, jak idzie w stronę białego światła. l...idaca w stronę białego światta.

Tamdolu bolo vidiet pohybovat'sa človeka. - Tam na dole widać było poruszajacego się człowieka. /... człowieka w ruchu.

Všimol si biely list papiera trepotat' sa pred dverami. - Zauważył białą kartke papieru, jak trzepoce się przed drzwiami. /...trzepoczaca przed drzwiami.

Naraz som zbadala prichádzat známeho čašníka. - Naraz zauważyłam, jak nadchodzi znajomy kelner. /... nadchodzacego znajomego kelnera.

Polskie ekwiwalenty słowackich predykatów nie realizują schematu

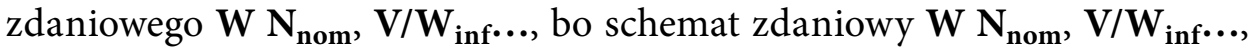
typowy dla języka słowackiego, gdzie argument zdarzeniowy ma postać konstrukcji z bezokolicznikiem (accusativus cum infinitivo), w języku polskim nie ma swojego ekwiwalentu i realizowany jest najczęściej w postaci schematu $\mathbf{W} \mathbf{N}_{\text {nom }}$, (Pron) Con V/W..., czyli argumentu zdarzeniowego w postaci zdania podrzędnego $\mathrm{z}$ verbum finitum lub $\mathbf{W} \mathbf{N}_{\text {nom }}, \mathbf{V A d j}_{\mathbf{a c c}} \ldots / \mathbf{W A d j} \mathbf{j}_{\mathbf{a c c}} . .$. , $\mathrm{tj}$. argumentu zdarzeniowego $\mathrm{w}$ postaci frazy nominalnej z imiesłowem przymiotnikowym czynnym. 


\section{3. $\mathrm{W} \mathrm{N}_{\mathrm{x}}, \mathrm{NV} / \mathrm{NW}_{\mathrm{q}} \ldots$}

Czasowniki słowackie: cítit', nájst', počut', predstavit' si, u/vidiet', uzriet', všimnút’ si, zbadat’

Czasowniki polskie: czuć, dostrzec, u/słyszeć, widzieć, wyobrazić sobie, zastać, zauważyć

\section{Schemat zdaniowy}

$\mathbf{W} \mathbf{N}_{\text {nom }}, \mathbf{N}_{\text {acc }}$

Cítil na sebe milenkin pohlad. - Czuł na sobie spojrzenie kochanki.

Básnik našiel inšpiráciu pre svoje texty. - Poeta znalazł inspirację dla swoich tekstów. Rozhlasový poslucháč počul kašlanie moderátora. - Radiostuchacz ustyszał kaszel spikera.

Pavol si v duchu predstavil jej príchod. - Paweł wyobraził sobie w duchu jej przyjazd. Uvidel som údiv na tvárach svojich kamarátov. - Dojrzałem podziw na twarzach swoich kolegów.

Jana vidí význam svojej práce. - Jana widzi sens swojej pracy.

Všímol si matkinu neprítomnost'. - Zauważył nieobecność matki.

Neskoro sme zbadali pokles formy. - Zbyt późno dostrzegliśmy spadek formy.

Schemat zdaniowy $\mathbf{W} \mathbf{N}_{\text {nom }}, \mathbf{N}_{\text {acc }}$ gdzie fraza nominalna w bierniku jest wykładnikiem argumentu zdarzeniowego, jest realizowany jednakowo w obu językach, tj. argument zdarzeniowy ma postać nazwy abstrakcyjnej - rzeczownika odczasownikowego lub odprzymiotnikowego.

\section{4. $\mathrm{W} \mathrm{N}_{\mathrm{x}}, \mathrm{N}_{\mathrm{aq}} \mathrm{V} / \mathrm{W}_{\mathrm{q}} \ldots$}

Czasowniki słowackie: nájst', počut', pozorovat', predstavit si, u/vidiet', zbadat'

Czasowniki polskie: dostrzec, obserwować, u/słyszeć, widzieć, wyobrazić sobie, zastać, zauważyć

\section{Schemat zdaniowy}

$\mathbf{W} \mathbf{N}_{\text {nom }}, \mathbf{N}_{\text {acc }}$ Con V/W...

Štefan našiel ženu, ako sedí na gauči. Stefan zastał żonę, jak siedzi na tapczanie. /...siedzaca na tapczanie.

Počul brata, ako kričí. - Ustyszał brata, jak krzyczy.

Pozoroval ho, ako odchádza v tme. - Obserwowat go, jak odchodzi w ciemności. l...odchodzacego w ciemności.

Predstavil si otca, ako ho čaká doma. - Wyobraził sobie ojca, jak go czeka w domu. l... go czekajacego $w$ domu.

Jurko uvidel mladé tanečnice, ako prezentujú svoj program. - Jurko zobaczył młode tancerki, jak prezentują swój program. /...prezentujace swój program 
Maria Papierz Konstrukcje z predykatami percepcji w języku słowackim i ich ekwiwalenty...

Videla som chlapčeka, ako sa hrá so svojim psom. - Widziałam chłopca, jak bawi się ze swoim psem. /...bawiącego się ze swoim psem.

Zbadal som brata Kirkora, ako beží ulicou. - Dostrzegłem brata Kirkora, jak biegnie ulica. ....biegnącego ulicą.

Polskie ekwiwalenty realizują również schemat zdaniowy:

$\mathbf{W} \mathbf{N}_{\text {nom }}, \operatorname{VAdj}_{\mathbf{a c c}} \ldots / \mathrm{WAdj}_{\mathrm{acc}} \ldots$

\section{5. $\mathrm{W} \mathrm{N} \mathrm{N}_{\mathrm{x}}, \mathrm{N}_{\mathrm{aq}} \emptyset_{\mathrm{q}}$}

Czasowniki słowackie: cítit', nájst', počut', pozorovat', predstavit’ si, u/ vidiet', uzriet', všimnút si, zbadat'

Czasowniki polskie: czuć, dostrzec, u/słyszeć, widzieć, wyobrazić sobie, zastać, zauważyć

$\mathbf{W} \mathbf{N}_{\text {nom }}, \mathbf{N}_{\text {acc }}$

Pavol sa vrátil a našiel doma hosta. - Paweł wrócił i zastał w domu gościa.

Už na schodoch počula manžela. - Już na schodach styszała męża.

Ondrej si predstavil nebohého otca. - Ondrej wyobraził sobie zmarlego ojca.

Chlapec uvidel v parku veveričku. - Chłopiec zobaczył w parku wiewiórkę.

Vidi krehké pavučinky babieho leta. - Widzi delikatne pajęczynki babiego lata.

Všimla si klúče vo dverách garaże. - Zauważyła klucze w drzwiach garażu.

Zrazu turisti zbadali zámok. - Nagle turyści dostrzegli zamek.

Schemat zdaniowy $\mathbf{W} \mathbf{N}_{\text {nom }}, \mathbf{N}_{\mathrm{acc}}$ dla fraz zdaniowych nr 4. $\mathbf{W} \mathbf{N}_{\mathrm{x}}, \mathbf{N}_{\mathrm{aq}} \boldsymbol{\emptyset}_{\mathrm{q}}$ ma tę samą postać jak dla fraz nr 3. W $\mathbf{N}_{\mathbf{x}}, \mathbf{N V} / \mathbf{N W}_{\mathbf{q}} \ldots$, ale w schematach zdaniowych dla frazy nr 3 ,ślad” predykacji zawiera jej wykładnik w postaci nazw abstrakcyjnych (rzeczowników odczasownikowych lub odprzymiotnikowych), natomiast w schematach dla frazy $\mathrm{nr} 4$ nazwy rzeczowe jako kondensaty struktury predykatowo-argumentowej wymagają znajomości kontekstu w celu odtworzenie tej struktury.

\section{Podsumowanie}

Argument zdarzeniowy implikowany przez predykaty percepcji słuchowej i wzrokowej o strukturze semantycznej P (x, q), należące do predykatów II rzędu o jednym argumencie przedmiotowym $\mathrm{i}$ jednym argumencie zdarzeniowym (propozycjonalnym) zarówno w języku słowackim, jak i w języku polskim może być realizowany na powierzchni $\mathrm{w}$ formie zdania podrzędnego $\mathrm{z}$ verbum fini- 
Maria Papierz Konstrukcje z predykatami percepcji w języku słowackim i ich ekwiwalenty...

tum oraz w postaci konstrukcji składniowych o różnym stopniu kondensacji. Schematy zdaniowe nr 1, 3, 4 i 5 są tożsame w języku słowackim i polskim, natomiast schemat $\mathrm{nr} 2$ (z bezokolicznikiem jako kondensatem argumentu zdarzeniowego) występuje tylko w języku słowackim, a polszczyzna ma tu inne odpowiedniki, co znajduje swoje odzwierciedlenie w opisie metajęzykowym, glottodydaktyce, a także praktyce tłumaczeniowej.

\section{Bibliografia}

\section{Literatura przedmiotu}

Grzesiak, R. (1983). Semantyka i składnia czasowników percepcji zmysłowej. Wrocław: Zakład Narodowy im. Ossolińskich.

Jodłowski, S. (1976). Podstawy składni polskiej. Warszawa: PWN.

Jedlička, A. (Red.). (1977). Slovník slovanské lingvistické terminologie (T. 1). Praha: Academia Kačala, J. (1971). Doplnok v slovenčine. Bratislava: Vydavat. Slovenskej Akad. Vied.

Karolak, S. (1984). Składnia wyrażeń predykatywnych. W: Z. Topolińska (Red.), Gramatyka współczesnego języka polskiego: Składnia. Warszawa: PWN.

Karolak, S. (2002). Podstawowe struktury składniowe języka polskiego. Warszawa: Slawistyczny Ośrodek Wydawniczy.

Kiklewicz, A., Korytkowska, M., Mazurkiewicz-Sułkowska, J., Zatorska, A., \& Ramza, T. (2010). Podstawowe struktury zdaniowe współczesnych języków słowiańskich: białoruski, bułgarski, polski (A. Kiklewicz \& M. Korytkowska, Red.). Olsztyn: Centrum Badań Europy Wschodniej Uniwersytetu Warmińsko-Mazurskiego.

Oravec, J., \& Bajzíková, E. (1986). Súčasný slovenský spisovný jazyk: Syntax. Bratislava: Slovenské Pedagog. Nakl.

Papierz, M. (1994). Krótka gramatyka języka słowackiego. Warszawa: Wydawnictwa Szkolne i Pedagogiczne.

Papierz, M. (2013). Podstawowe struktury składniowe współczesnego języka słowackiego. Kraków: Wydawnictwo Lexis.

Papierz, M. (2013). Slovo a tvar v syntaxi: Od významu k forme v základných predikátovo-argumentových štruktúrach. W: Zborník Filozofickej Fakulty Univerzity Komenského. Philologica LXXII: Slovo a tvar v štruktúre a v komunikácii (ss. 377-383). Bratislava: Univerzita Komenského.

Pauliny, E. (1981). Slovenská gramatika. Bratislava: SPN.

Polański, K. (Red). (1999). Encyklopedia językoznawstwa ogólnego (2. wyd. popraw.). Wrocław: Ossolineum. 
Maria Papierz Konstrukcje z predykatami percepcji w języku słowackim i ich ekwiwalenty...

Sokolová, M., Vojteková, M., Mirosławska, W., \& Kyselová, M. (2012). Slovenčina a polština: Synchrónne porovnanie s cvičeniami. Prešov: Prešovská univerzita v Prešove.

Tibenská, E. (2012). Sémantická štruktúra slovenskej vety. Trnava: Univ. Sv. Cyrila a Metoda v Trnave.

Topolińska, Z. (1977). Mechanizmy nominalizacji w języku polskim. W: Z. Topolińska (Red.), Studia gramatyczne I (ss. 175-212). Wrocław: Zakład Narodowy im. Ossolińskich.

\section{Ekscerpowane źródła}

Buzássyová, K., \& Jarošová, A. (2006). Slovník súčasného slovenského jazyka (T. 1). Bratislava: VEDA. Buzássyová, K., \& Jarošová, A. (2011). Slovník súčasného slovenského jazyka (T. 2). Bratislava: VEDA. Buzássyová, K., \& Jarošová, A. (2016). Slovník súčasného slovenského jazyka (T. 3). Bratislava: VEDA. Dubisz, S. (Red.). (2003). Uniwersalny słownik języka polskiego (T. 1-4). Warszawa: PWN.

Dunaj, B. (Red.). (1996). Słownik współczesnego języka polskiego. Warszawa: Wilga.

Kačala, J., \& Pisárčiková, M. (Red.). (2003). Krátky slovník slovenského jazyka (4. wyd.). Bratislava: VEDA.

Peciar, Š. (Red.). (1959-1968). Slovník slovenského jazyka (T. 1-6). Bratislava: Vydavatel'stvo Slovenskej Akad. Vied.

Slovenský národný korpus [w wersji prim-6-0-public-all]. (b.d.). Pobrano z http://korpus .juls.savba.sk

\section{Constructions with predicates of perception in Slovak and theirs equivalents in Polish}

\section{Summary}

The aim of this paper is to present a special type of syntactic constructions in Slovak language, namely, the accusativus cum infinitivo. Constructions of this kind are connected with predicates of visual and auditory perception: Videl Petra bežat., Počul Evu spievat'. In the traditional Slovak syntax, the infinitive in this constructions is characterized as a particular sentence element, so-called "doplnok" 'predicate complement.' The Polish equivalents of these constructions are subordinate clauses or participle constructions. The second part of the paper presents a Polish-Slovak comparative analysis of these predicates as propositional (semantic) sentence structures, based on Stanisław Karolak's model. 


\section{Konstrukcje z predykatami percepcji w języku słowackim i ich ekwiwalenty w języku polskim}

\section{Streszczenie}

Artykuł jest próbą opisu szczególnego typu konstrukcji składniowych występujących w języku słowackim, tj. accusativus cum infinitivo, które łączą się z predykatami percepcji wzrokowej i słuchowej: Videl Petra bežat., Počul Evu spievat. Bezokolicznik w takich konstrukcjach jest w tradycji słowackiej opisywany jako odrębna część zdania, tzw. „doplnok”. W języku polskim konstrukcje oddawane są przez zdania podrzędne lub konstrukcje imiesłowowe. W drugiej części artykułu zaprezentowano opis tych predykatów w duchu składni semantycznej w oparciu o model Stanisława Karolaka w ujęciu porównawczym słowacko-polskim.

Keywords: argument-predicative structure; second-order predicates; predicates of perception; Slovak-Polish comparative description

Słowa kluczowe: struktura argumentowo-predykatowa; predykaty drugiego rzędu; predykaty percepcji; słowacko-polski opis porównawczy

Maria Papierz, Professor Emerita, Institute of Slavonic Studies, Faculty of Philology, Jagiellonian University, Kraków Correspondence: maria.papierz@gmail.com

The article has been prepared at the author's own expense.

Competing interests: The author has declared she has no competing interests. 